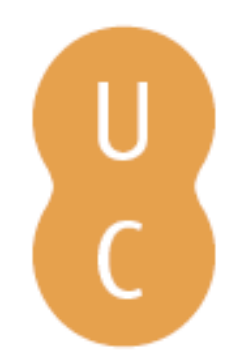

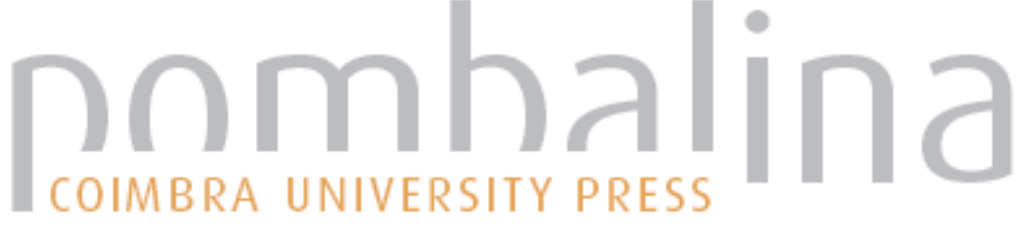

Miguel Bombarda e Manuel Fernandes Santana um confronto de ideias

\author{
Autor(es): $\quad$ Neto, Vítor \\ Publicado por: Imprensa da Universidade de Coimbra \\ URL \\ persistente: URI:http://hdl.handle.net/10316.2/32325 \\ DOI: $\quad$ DOI:http://dx.doi.org/10.14195/978-989-26-0362-9_12
}

Accessed : $\quad$ 26-Apr-2023 13:50:10

A navegação consulta e descarregamento dos títulos inseridos nas Bibliotecas Digitais UC Digitalis, UC Pombalina e UC Impactum, pressupõem a aceitação plena e sem reservas dos Termos e Condições de Uso destas Bibliotecas Digitais, disponíveis em https://digitalis.uc.pt/pt-pt/termos.

Conforme exposto nos referidos Termos e Condições de Uso, o descarregamento de títulos de acesso restrito requer uma licença válida de autorização devendo o utilizador aceder ao(s) documento(s) a partir de um endereço de IP da instituição detentora da supramencionada licença.

Ao utilizador é apenas permitido o descarregamento para uso pessoal, pelo que o emprego do(s) título(s) descarregado(s) para outro fim, designadamente comercial, carece de autorização do respetivo autor ou editor da obra.

Na medida em que todas as obras da UC Digitalis se encontram protegidas pelo Código do Direito de Autor e Direitos Conexos e demais legislação aplicável, toda a cópia, parcial ou total, deste documento, nos casos em que é legalmente admitida, deverá conter ou fazer-se acompanhar por este aviso.

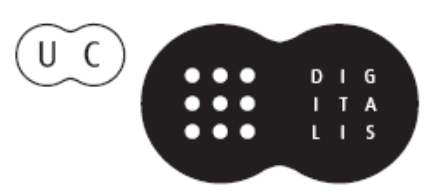


Ana Leonar Pereira Jםão Rui Pita [ Coordenaçä̃ ]

\section{Miguel Bomberda e as singularidades de uma época}

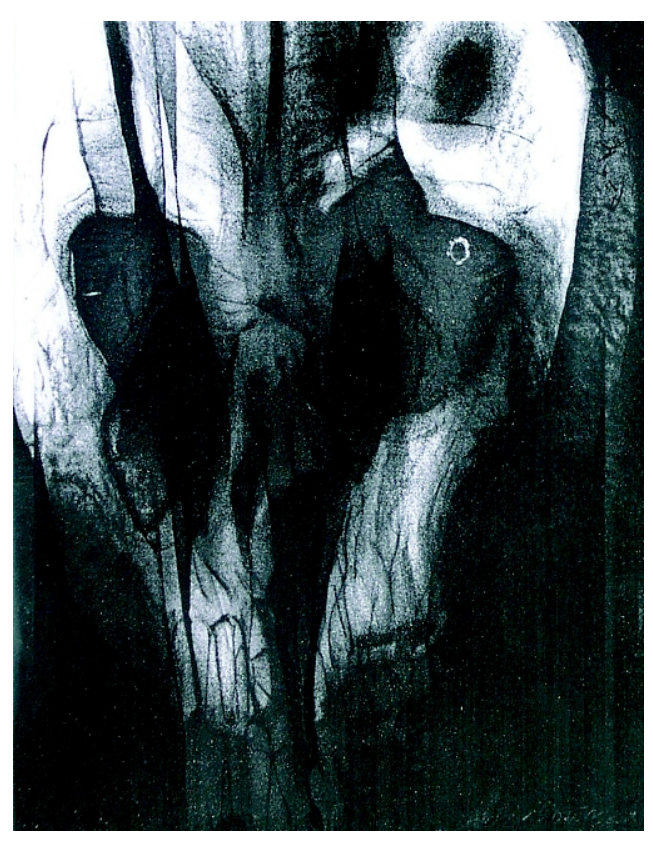


(Página deixada propositadamente em branco) 
Ana Leonor Pereira

João Rui Pita

(Coordenação)

\title{
FOLHA DE ROSTO
}

\author{
Miguel Bombarda (1851-1910)
}

a as singularidades de uma época 


\section{Coordenação Científica da Colecção Ciências e Culturas}

João Rui Pita e Ana Leonor Pereira

Os originais enviados são sujeitos a apreciação científica por referees

\section{Coordenação Editorial}

Maria João Padez Ferreira de Castro

\section{Edição}

Imprensa da Universidade de Coimbra

Email: impresauc@ci.uc.pt

URL: http://www.imp.uc.pt • Normas de publicação de colecções

Design

António Barros

Pré-Impressão

António Resende

Imprensa da Universidade de Coimbra

Capa

António Dantas. Sem título, 2002. Col. António Barros. Coimbra

Impressão e Acabamento

SerSilito • Maia

\section{ISBN}

978-989-8074-11-9

\section{Depósito Legal}

Obra publicada com a colaboração de:
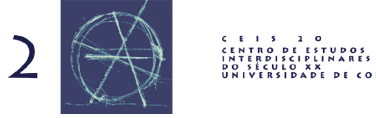

Obra publicada com o apoio de:

FCT Fundação para a Ciência e a Tecnologia

MINISTÉRIO DA CIÊNCIA, TECNOLOGIA E ENSINO SUPERIOR Portugal

Programa Operacional Ciência, Tecnologia, Inovação do Quadro Comunitário de Apoio III

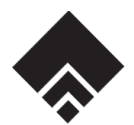

Fundaçāo Eng. António de Almeida

(C) Agosto 2006, Imprensa da Universidade de Coimbra 


\section{Vítor Neto}

Faculdade de Letras e CEIS20, Universidade de Coimbra, Portugal

\section{Miguel Bombarda e Manuel Fernandes Santana UM CONFRONTO DE IDEIAS}

Tendo como pano de fundo o intelectualismo iluminista que o inspirava e em ruptura com a cultura romântica que lhe era anterior, o cientismo impôs-se como paradigma cultural hegemónico ao nível das elites na segunda metade do século XIX. Para a nova crença no valor ilimitado da Ciência muito contribuiram os progressos da sociedade científico-industrial dos países mais avançados da Europa de então e as conquistas científicas alcançadas em novos domínios do saber. Como já foi sublinhado a reflexão sobre a Ciência, levada a efeito por vários intelectuais oitocentistas, radicava na ideia segundo a qual o mundo poderia ser objecto da análise, da compreensão racional e da explicação científica. Ora, ao emergir do interior da Ciência, ou à sua margem, o cientismo ${ }^{1}$ configurou-se como uma ideologia oposta à mundovisão espiritualista sustentada pela Igreja católica. Por outro lado, superava o carácter redutor de uma dimensão meramente científica para se situar num horizonte de unificação ideológica dos diferentes ramos do conhecimento. Ao nível das elites avançadas dos finais do século XIX e dos inícios do século XX, o cientismo serviu de legitimação a uma concepção dessacralizada do mundo e a um sistema de representaçôes do Universo antimetafísico e anti-teológico. Desta forma, os intelectuais que assumiam a nova cultura tentaram impor o triunfo do laicismo sobre o catolicismo já que a ideologia cientista desaguava, ao nível das mundividências, no agnosticismo ou no ateísmo ${ }^{2}$.

Em Portugal uma elite político-cultural também se afirmou primeiro através do positivismo e, mais tarde, do cientismo. Ora, foi no quadro de divulgação dos resultados da Ciência que surgiu Miguel Bombarda, intelectual bastante bem informado sobre a cultura científica do seu tempo. Julgo que o autor de A Consciência e o Livre Arbítrio (1898) - obra dedicada ao "Patriarca do Monismo» - interpretava, como poucos, os conhecimentos científicos dos últimos decénios do século XIX. Influenciado pelo mo-

\footnotetext{
${ }^{1}$ Sobre a evolução das ciências e a sua relação com o cientismo, na segunda metade do século XIX leia-se, por exemplo, Robert Schnerb, Le XIX Siècle. L'Apogée de L'Expansion Européenne (1815-1914), Paris, PUF, 1961, pp. 99-110. Para o conhecimento da evolução do positivismo ao cientismo veja-se Georges Bastide, Les Grands Thèmes Moraux de la Civilisation Occidentale, Paris, Bordas, pp. 199-228.

${ }^{2}$ Para o conhecimento do cientismo como ideologia leia-se Fernando Catroga, Cientismo e Historicismo, pp. 2-8 (artigo policopiado).
} 
nismo naturalista de Buchner e $\mathrm{Haeckel}^{3}$, Bombarda encetou o processo de construção de uma ontologia a partir dos resultados das ciências da natureza e da sociedade. Ao dispensar a metafísica da sua concepção do mundo, o professor da Escola Médico-Cirúrgica de Lisboa identificava Deus com o Universo caindo assim numa posição panteísta à maneira de Spinoza. Perante as posições ideológicas do «Haeckel português» não nos surpreende que a Igreja católica, na linha da contra-ofensiva lançada contra o pensamento progressista a partir do Concílio Vaticano I, respondesse ao desafio do livre-pensador através de um dos seus membros mais esclarecidos em questôes de natureza filosófica e informação científica, o padre jesuíta Manuel Fernandes Santana. Assim, um ano após a publicação do livro de Miguel Bombarda, o jornal Correio Nacional - orgão oficial do episcopado - começou a publicar uma série de artigos os quais seriam, mais tarde, reunidos em dois volumes intitulados $\mathrm{O}$ Materialismo em Face da Ciência (1900). Confontado com uma visão do mundo que colidia com a sua e com uma agressividade inaudita da parte do professor jesuíta, Bombarda reagiu e lançou a lume, ainda nesse ano, A Ciência e o Jesuítismo. Réplica a um padre sábio ${ }^{4}$. No conjunto da sua obra, o intelectual materialista assumiu-se como cientista ${ }^{5}$, mas também como divulgador de ideias, polemista e anticlerical.

A obra do autor distanciava-se do positivismo de Augusto Comte e inseria-se numa perspectiva claramente cientista. Tal significava a assunção de uma concepção totalizante da natureza, do Homem e na consequente rejeição da cosmogonia judaico-cristã ${ }^{6}$. Influenciado por Haeckel, Moleschott, Verworn, Vogt, Buchner e Darwin, Miguel Bombarda utilizava os seus conhecimentos nos domínios da biologia, da sociologia e da psicologia experimental para fundamentar a sua teorização sobre a ontologia por um lado e a gnosiologia pelo outro. No que se refere ao cosmos, retomava a herança do materialismo antigo, do mecanicismo cartesiano e das ideias avançadas pelo filósofo Iluminista La Mettrie. Se em Descartes o Homem já era visto como uma máquina, no século XVIII, a corrente filosófica materialista retomava esta imagem e procurava expulsar as concepções metafísicas da vida biológica e social ${ }^{7}$. Bombarda iluminava as visões mecanicistas do ser humano dos séculos XVII e XVIII com os conhecimentos obtidos pelo monismo naturalista na segunda metade do século XIX. Rejeitando o causalismo finalista fundado na metafísica, entendia o Universo como a expressão das diferentes gradações do ser, desde o mundo físico até ao Homem. Este era entendido como a expressão última de uma cadeia piramidal organizada no sentido de uma complexidade e heterogeneidade crescentes à maneira de Spencer. Nesta perspectiva, havia uma linha de continuidade entre "os seres inorgânicos até à mais cultivada célula psíquica». Porém, ao acreditar na teoria da geração espontânea não deixava de

\footnotetext{
${ }^{3}$ Sobre o monismo naturalista e os seus reflexos em Portugal veja-se Manuel Louzã Henriques, As Concepçôes Materialista, Positivista e Evolucionista e a Psiquiatria Portuguesa, Coimbra, Unitas, 1966, pp. 53-130. (Dissertação de licenciatura apresentada à Faculdade de Medicina).

${ }^{4}$ Vítor Neto, O Estado, a Igreja e a Sociedade em Portugal (1832-1911), Lisboa, INCM; 1998, p. 505.

${ }^{5}$ Sobre Miguel Bombarda enquanto psiquiatra materialista leia-se, Manuel Lousã Henriqes, ob. cit., pp. 207-267.

${ }^{6}$ Fernando Catroga, A Militância Laica e a Descristianização da Morte em Portugal 1865-1911, Coimbra, 1988, p. 226. (Dissertação de Doutoramento mimeografada).

${ }^{7}$ Idem, Cientismo e Historicismo, pp. 10-11.
} 
chamar a atenção para o facto de a Ciência ainda não a ter demonstrado ${ }^{8}$. A origem do Homem ${ }^{9}$ resultava de um processo mecânico e não de uma causalidade finalista e a consciência reduzia-se a uma consequência físico-químico do cérebro. Recorrendo à psicologia experimental ${ }^{10}$ (Wundt, Fechner, Weber e Exner), via naquela «um epifenómeno", "um acessório, um facto acidental» ${ }^{11}$. Se a ontologia remetia para uma concepção naturalista do ser humano, a gnosiologia tinha uma base empirista e associacionista ${ }^{12}$. Rejeitando, em consequência, a verdade revelada pensava que o Homem tinha capacidade para obter o conhecimento das leis invariáveis dos mundos físico e orgânico. Porém, o cientista, cingido à realidade fenoménica, não teria que se preocupar com as causas últimas. Ao referenciar os limites da Ciência não deixava de afirmar: "Onde ela se espanta, aí sim, é quando, tendo reduzido o Universo ao singelo movimento dos átomos, pergunta pela razão do Existente. Mas então, parece-me bem, acha-se no limiar do Incognoscível» ${ }^{13}$. O agnóstico Bombarda colocava-se em sintonia com o panteísmo de Haeckel autor que não hesitava em afirmar na sua obra sobre o monismo que: «Parmi les divers systèmes de pentheísme que l'idée moniste de Dieu a depuis longtemps inspirés d'une manière plus ou moins claire, celui de Spinoza est de beaucoup le plus parfait. On sait que Goethe accordait aussi à ce système sa haute admiration et son adhésion» ${ }^{14}$.

\footnotetext{
${ }^{8}$ Ao escrever sobre esta teoria afirmava: "Em todo o caso, deve-se dizer que a geração espontânea dos corpos vivos, que tem sido objecto das mais afincadas indagaçōes experimentais, ainda não foi demonstrada. Sabe-se como Pasteur mostrou as causas de erro de todos os experimentadores que se tinham ocupado da questão. Todavia do seu trabalho não resulta que a geração espontânea não exista ou não tenha existido, mas apenas que a sua demonstração ainda não foi realizada”. Miguel Bombarda, A Conciência e o Livre Arbitrio, Lisboa, 2a ed., Parceria António Maria Pereira, 1902, p. 29.

${ }^{9}$ Sobre a origem da vida e do próprio Homem concluía: "Ora a natureza viva inteira, no tempo e no espaço, não teve por origem senão plastides. Um ser vivo, qualquer que seja a sua elevação orgânica, o homem mesmo, começou sempre por ser um elemento plastidar. Plastide é o óvulo e agregado de plastides é o homem. Se no óvulo não há em função senão energias mecânicas, como podemos encontrar outras no homem?", Idem, Ibidem, p. 35.

${ }^{10}$ Miguel Bombarda conhecia o extraordinário desenvolvimento deste ramo de conhecimento na sua época como se comprova com a seguinte passagem: "Os laboratórios de psicologia experimental têm-se multiplicado; só na América Binet conta 30 e uns 20 no resto do mundo. Revistas especiais têm aparecido na Alemanha, nos Estados-Unidos, na França. O material de instrumentos e aparelhos tem atingido a última perfeição. E todos os anos são aos milhares os trabalhos que se publicam e em que a psicologia é rebuscada nos seus mais obscuros recantos. Só a bibliografia do último Ano Psicológico de Binet enumera 2234 trabalhos". Idem, Ibidem, p. 258.

${ }^{11}$ Idem, Ibidem, p. 52

${ }^{12}$ Fernando Catroga, A Militância Laica e a Descristianização da Morte em Portugal 1865-1911, Coimbra, 1988, pp. 234-235. No que concerne à gnosiologia Miguel Bombarda é claro: "A ciência só se constrói sobre a observação e a experiência; a razão acompanha os factos colhidos para os desenvolver, comparar e interpretar, para estabelecer as relações que os ligam entre si, para levantar hipóteses que nova confirmação experimental confirmará ou invalidará, para descobrir as leis gerais que os abrangem num laço único». Miguel Bombarda, A Ciência e o Jesuitismo. Réplica a um padre sábio, Lisboa, Parceria António Maria Pereira, 1900 , p. 25.

${ }^{13}$ Miguel Bombarda, ob. cit., p. 12.

${ }^{14}$ Ernest Haeckel, Le Monisme. Profession de foi d'un naturaliste, Paris, Scheicher Frères, Éditeurs, s. d., p. 55.
} 
Como Edgar Morin mostrou o determinismo - assumido pelos propugnadores da ideologia cientista - é hoje considerado um verdadeiro mito na medida que não responde, enquanto modelo explicativo, à complexidade dos fenómenos do Universo. Se é certo que a problemática do determinismo tem uma história cuja origem se encontra no mundo antigo desenvolvendo-se posteriormente na Idade Média, na modernidade e nos séculos XIX e XX ${ }^{15}$, também é verdade que a querela filosófica sobre o assunto ainda não se encontra completamente encerrada. Ao superar filosoficamente as concepções deterministas este pensador veio chamar a atenção para a necessidade de se encararem os fenómenos físicos, biológicos e antropo-sociais numa perspectiva de relacionamento entre a ordem e a desordem, a necessidade e o acaso, a contingência, o aleatório, o incerto, o impreciso, o indeterminado e o complexo. Como se o Universo exigisse uma Ciência Nova que compreendesse a microfísica, a cosmofísica e a termodinâmica ${ }^{16}$. Contudo, a seu ver, a realização do progresso prodigioso dos conhecimentos científicos correlaciona-se com o desenvolvimento simultâneo da ignorância.

Miguel Bombarda escreveu a sua obra nos finais do século XIX e nos inícios do século XX e, por isso, não pôde escapar às concepções do mundo que radicavam no determinismo cósmico e no fatalismo evolucionista que caracterizavam o materialismo da época. Segundo ele: «A invariabilidade de relacionamento fenomenal, que permite o estabelecimento dessas leis, é o que constitui o determinismo, que não significa outra coisa senão que em presença de determinadas condiçôes os fenómenos se desenrolarão por um modo matematicamente certo» ${ }^{17}$. Se o Homem era entendido como uma máquina que agia no interior de um cosmos ordenado e harmonioso, o pensamento também se inscrevia nessa visão mecanicista do Universo. O autor definia a sociedade como um organismo que se consubstanciava nos indivíduos que a compunham e na relação que estes estabeleciam com o meio em que se integravam. Permitindo captar as leis sociais e aniquilar as "fantasias metafísicas», a sociologia ${ }^{18}$ funcionava como um prolongamento das ciências biológicas ${ }^{19}$. Nessa sequência, ao rejeitar a alma - «como noção científica», essa "hipótese» (...) «é absolutamente sem base» ${ }^{20}$ - e ao negar diferenças qualitativas entre o Homem e outras esferas do ser, Bombarda abria caminho à luta pela descristianização da sociedade o que pressepunha a rejeição de todas as formas de manifestação religiosa ${ }^{21}$.

Opositor das leis pré-estabelecidas reivindicadas pelo vitalismo de $\mathrm{Cl}$. Bernard, cingia-se à análise do mundo fenoménico ${ }^{22}$. Recusando a doutrina do livre-arbítrio

15 Sobre a história do determinismo leia-se Krzysztof Pomian, "Le déterminisme: histoire d'une problématique», Le débat, Paris, Gallimard, 1990, pp. 11-58.

${ }^{16}$ Edgar Morin, "Au-delà du déterminisme: le dialogue de l’ordre e du désordre», Le débat, Paris Gallimard, 1990, pp. 93-98.

${ }^{17}$ Miguel Bombarda, op. cit., p. 14.

${ }^{18}$ Sobre a influência do positivismo e do cientismo na fase inicial da sociologia no nosso país veja-se Amadeu Carvalho Homem, "Ilusōes do Cientismo nos Primórdios da Sociologia Portuguesa", Da Monarquia à República, Viseu, Palimage Editores, 2001, pp. 159-173.

${ }^{19}$ Fernando Catroga, ob. cit., p. 236.

20 Sobre a hipótese da alma veja-se Miguel Bombarda, ob. cit., pp. 245-253.

${ }^{21}$ Fernando Catroga, ob. cit., p. 236.

${ }^{22}$ Miguel Bombarda, ob. cit., p. 17. 
tinha como objectivo dessacralizar o Homem ao procurar que ele deixasse de ser visto como mero reflexo da vontade divina. Nesta perspectiva, criticava a autosuficiência das filosofias espiritualistas que retomavam a herança da escolástica enriquecida com o desenvolvimento do pensamento filosófico dualista posterior. O nosso autor não negava a ideia de liberdade, mas inseria-a numa visão cientista da natureza e da sociedade. Tal ideia só seria realizável desde que o Homem subordinasse a sua actividade ao normativismo imposto pela realidade objectiva. Assim, como já foi justamente sublinhado, a margem de intervenção dos indivíduos situava-se no espaço existente entre as realidades de facto e o que era exigido pela determinação da evolução histórica ${ }^{23}$.

Se bem que o cientismo não se apresentasse como uma utopia pelo conteúdo das suas ideias não deixa de se situar no imaginário de uma aspiração a uma outra realidade que rompia com a existente. Em Miguel Bombarda não se encontra qualquer esforço de teorização utópica, ao colocar a Humanidade como sujeito e motor da história, não deixava de se voltar para o futuro criando a esperança de concretização de uma utopia de teor cientista. "A ciência, guiada pela fatalidade das suas aquisições, será a grande arma de combate. A legislação terá - exclusivamente - que se inspirar nas suas convicçóes. E quando essa exclusiva inspiração vier, quando o homem se tiver penetrado da ideia do seu fim e da sua força, quando as sociedades compreenderem que todo o mal tem as suas condiçôes de produção e que, abolidas estas, o mal será abolido, quando se tiverem feito ouvir ou se tiverem imposto as vozes que reclamam tantas e tantas providências urgentes - desde a legislação do trabalho até à socialização do solo, desde o imposto progressivo até à separação da igreja e do estado, - quando os interesses de classe começarem a embotar-se e o ideal humano tiver infiltrado os espíritos, a fraternidade deixará de ser um mito e a humana felicidade uma utopia» ${ }^{24}$. Atento aos problemas sociais resultantes do capitalismo, Bombarda sonhava com um mundo menos injusto e mais solidário. Neste sentido, interrogava-se acerca da realização histórica da ideia utópica: «É fazer socialismo? Será. Porque não? Se o socialismo está na evolução fatal da humanidade, se é precisamente no socialismo que sorri a aurora da renascença do homem e começa a entreabrir-se uma era de justiça e de solidariedade, uma era de condenação de todos os egoísmos!» ${ }^{25}$ Como se vê, o cientismo acabava por desaguar num humanismo e numa solidariedade social subordinados a uma moral cientificamente demonstrada. Como Fernando Catroga mostrou, numa das suas obras, ao dessacralizar a natureza, o Homem, a história e o saber, Miguel Bombarda construía uma mundividência totalizante que emergia como alternativa à visão globalizadora do Homem e da natureza defendida pelo catolicismo ${ }^{26}$.

$\mathrm{Na}$ sua resposta ao autor de A Consciência e o Livre Arbítrio, Fernandes Santana começava por atacar o materialismo classificando os seus adeptos como «uma seita fanática filosófica-religiosa ${ }^{27}$. Ao dirigir as suas críticas a Haeckel, procurava

\footnotetext{
23 Idem, Ibidem.

${ }^{24}$ Miguel Bombarda, ob. cit. p. 362.

${ }^{25}$ Idem, Ibidem, pp. 362-363.

${ }^{26}$ Fernando Catroga, ob. cit., p. 276.

27 Sobre a definição da "seita" e a origem e desenvolvimento das concepções materialistas veja-se Manuel Fernandes Santana, $O$ materialismo em face da ciência a proposito da consciência e livre arbitrio do sr. prof. Miguel Bombarda, vol. 1, Lisboa, Typographia da Casa Catholica, 1899, pp. 14-27.
} 
estabelecer a génese e evolução da concepção monista do Universo e, em nome da filosofia dualista, rejeitava as teses do naturalista alemão. Criticando este pensador também atingia Miguel Bombarda que, como se viu, lhe dedicara a sua obra. O padre jesuíta via em Deus o "Supremo arquitecto» e "o Supremo autor do universo» 28 . Portador de uma cosmogonia que remetia para a entidade divina a origem da matéria e do movimento usava uma vasta bibliografia em apoio das suas teses ancoradas na metafísica. A essa luz combatia o materialismo mecanicista e reafirmava a filosofia espiritualista que, como se sabe, estabelecia uma divisão entre o corpo e a alma. Ao rejeitar a concepção do mundo baseada no movimento atomístico da matéria também não perfilhava a ideia do Homem máquina nem aceitava a definição do pensamento como um simples produto do cérebro. Criado por Deus à sua imagem e semelhança, o indivíduo ocupava o centro do mundo e representava a síntese de todos os seres que povoavam o cosmos. Dotado de inteligência e liberdade subjectiva, o Homem tinha capacidade de agir sobre a realidade física ${ }^{29}$ contrariando, assim, o determinismo psíquico defendido por Bombarda ${ }^{30}$.

Ao afirmar que a alma era um princípio de vida superior no Homem, o padre jesuíta assumia-se como herdeiro das filosofias dualistas antigas (Hipócrates, Platão, Sócrates e Aristóteles), retomava algumas das ideias do pensamento medieval (Alberto Magno e S. Tomás de Aquino) e enunciava os princípios do catolicismo tal como a Igreja os definira no século XIX. Segundo Fernandes Santana, o materialismo oitocentista fora o ponto de chegada de um longo movimento de ideias cujas origens se situavam no Renascimento (Paracelso e Van Helmont), tinha prosseguido com Descartes e Leibnitz no século XVII e teria culminado nos positivismos de Augusto Comte, Litrré, Stuart Mill e outros. Como se sabe, ao substituir a ideia de Deus pela da Humanidade e ao fazer desta o sujeito da história, Comte pretendera dar o golpe de morte à metafísica substituindo-a pelo estado positivo. Fernandes Santana sabia que a doutrina positivista beneficiara dos contributos de Locke, Condillac, Cabanis, Broussais e que, entre outros caminhos, evoluira para o monismo naturalista de Haeckel. Porém, ao combater o pensamento mais avançado qualificava o intelectual alemão como um «falsificador da ciência» ${ }^{31}$, criticava o fisiologista Magendie por este ter rejeitado o causalismo final na explicação dos fenómenos vitais e contestava $\mathrm{Cl}$. Bernard por ele aderir à filosofia espiritualista tradicional. Por fim, voltava-se contra Virchow que, na sua óptica, não só desconhecia as filosofias subjectivistas como divulgava um «ensino eivado de contradições grosseiras» ${ }^{32}$.

Apesar da erudição que lhe permitia escrever sobre os nomes mais célebres da «ciência biológica» - Haeckel, Virchow, Darwin, Cl. Bernard e Du-Bois-Reymon - Fernandes Santana estaria, no dizer de Miguel Bombarda, cientificamente desactualizado em cerca de trinta anos. Ao referir-se ao seu desconhecimento das conquistas científicas mais recentes afirmava: «apenas nenhuma citação dos biologistas dos infinitamente pequenos,

${ }^{28}$ Idem, Ibidem, p. 104.

${ }^{29}$ Idem. Ibidem, p. 8.

30 Para o conhecimento da argumentação usada contra o determinismo leia-se Idem, Ibidem, vol. 2, pp. 340-428.

${ }^{31}$ Vítor Neto, ob. cit., p. 510.

${ }^{32}$ Manuel Fernandes Santana, ob. cit., pp. 23-25. 
dos biologistas do microscópio, que têm reconstruído a ciência da vida sobre a base dos seres unicelulares - os Verworn, Hertwig, Engelmann, Peffefer, Mendelssohn e tantos, tantos outros, que vieram dar inesperada confirmação às teorias mais gerais da vida; do mesmo modo que noutro campo se não citavam nunca os Ziehnen, os Ramon y Cajal, os Waldeyer, os Kolliker ... que construiram as doutrinas psicológicas modernas ou lhes forneceram o mais sólido fundamento» ${ }^{33}$. O padre jesuíta atacava com virulência os pensades materialistas, ou todos aqueles que contrariavam a filosofia católica. Assim, "Haeckel é um míope que se lança a todo o galope pelas vastas campinas do absurdo e do rídiculo. Goltz é um idiota. Buchner um falsificador. Descartes um observador superficial. Helmhotz um inepto e um insensato. Beaunis um demente e um ingénuo. Darwin um naturalista nem sério nem consciencioso. Cl. Bernard uma bela inteligência esterilizada pelo empirismo animal. Herzen, tão audaz, como inconsequente, caindo em grosseiras contradiçôes. Matias Duval um ignorante presunçoso. E para coroamento troça-se de Moleschott, um dos espíritos mais eminentes do nosso século científico» ${ }^{34}$. Como se vê, à argumentação utilizada pelas figuras mais eminentes da Ciência, o professor do Colégio de Campolide respondia com «injúrias» e "calúnias». Ao materialismo opunha a metafísica - por ele considerada a ciência das ciências - e o finalismo causalista era visto como um problema inerente à Ciência. Declarando a possibilidade de acesso a Deus por via racional, o jesuíta recorria a uma argumentação estritamente especulativa que não poderia ser aceite pelos cientistas. Adversário do evolucionismo e da cosmologia mecanicista atribuía ao Homem inteligência e uma capacidade autónoma de moldar a realidade. Por outro lado, criticava a influência de Darwin em Miguel Bombarda através da teoria da selecção natural, opunha-se ao determinismo psicológico, à autosuficiência da matéria e à moral científica ${ }^{35}$. Este combate de ideias, aqui brevemente enunciado, fazia-se em nome do catolismo e das filosofias espiritualistas que o fundamentavam.

À longa obra de Fernandes Santana respondeu Bombarda, com o seu opúsculo A Ciência e o Jesuitismo, cujo conteúdo representava um verdadeiro ataque ao clericalismo. Neste livro, o médico retomava a concepção monista do universo, voltava a rejeitar a verdade revelada, enfatizava o experimentalismo como método para a obtenção da verdade científica e contestava os obstáculos levantados pela Bíblia à emancipação do saber. Às teses do padre jesuita, respondeu Bombarda com a ideologia que brotava espontaneamente da prática científica nos laboratórios que funcionavam na Europa e na América do Norte. Contudo, se a visão católica do mundo era substítuida por uma concepção monista do universo não deixava de funcionar também como uma «religião». Na verdade, Miguel Bombarda acabaria por definir o monismo como uma nova «religião» tal como já o fizera Haeckel. Enfim, a polémica entre Bombarda e o padre Santana exprimia a oposição de duas concepções antagónicas do mundo e traduzia a impossibilidade do diálogo entre o cientismo e o catolicismo.

\footnotetext{
${ }^{33}$ Miguel Bombarda, A Ciência e o Jesuitismo. Réplica a um padre sábio, Lisboa, Parceria António Maria Pereira, 1900, p. 48.

${ }^{34}$ Idem, Ibidem, pp. 48-49.

${ }^{35}$ Vítor Neto, ob. cit., pp. 511-512.
} 
Resumo - No quadro da divulgação da ideologia cientista, Miguel Bombarda assumiu-se como um dos intelectuais mais esclarecidos. Ao assumir uma concepção monista do universo contrariava o conservadorismo ideológico sustentado pelos pensadores católicos. Por isso, a Igreja recorreu ao desafio lançado pelo materialismo de Bombarda através de um dos seus membros mais esclarecidos, o jesuíta Manuel Fernandes Santana. Influenciado pelos pensadores materialistas - Haeckel, Molescholt, Verworn, Vogt, Buchner e Darwin -, o professor da Escola Médico-Cirúrgica utilizava os seus conhecimentos nos domínios da biologia, da sociologia, da psicologia experimental e de outras ciências para fundamentar a sua teorização sobre as origens da vida, a auto-suficiência da matéria, a consciência do homem e a moral. Ao assumir a ideia de ciência e ao acreditar na obtenção da verdade científica por via racional, contestava as visóes ideológicas do universo. Contudo, o determinismo cósmico anulava - a nosso ver - a ideia de liberdade já que o ser humano ficava desprovido da capacidade de orientação da sua actividade. Por isso, a submissão do homem a um causalismo cego e a rejeição do livre-arbítrio levavam Bombarda a eliminar, em certa medida, o valor do homem e da liberdade. Desconhecendo o materialismo dialéctico aprisionava o indivíduo nas malhas de um universo fechado, subordinado à fatalidade de um movimento fenoménico predeterminado por um causalismo imanentista.

Ao monismo de Miguel Bombarda, opôs o padre Manuel Fernandes Santana uma concepção dualista do cosmos. Para ele, a ordem do fora preestabelecida por Deus e a matéria, o movimento, as energias cósmicas e a sua orientação inicial encontravam a sua explicação última no supremo arquitecto que o concebera. Nesta perspectiva, o sacerdote recusava o materialismo mecanicista e reafirmava a doutrina católica consubstanciada numa visão que radicava numa ligação entre o corpo e a alma. Criado à imagem e semelhança de Deus, o homem tinha capacidade para agir sobre o mundo que o rodeava. Desta forma, Fernandes Santana refutava o determinismo sustentado por Miguel Bombarda, mas caía numa concepção dualista sem qualquer base científica. A polémica entre os dois intelectuais exprimia o radicalismo de discursos opostos que emergiam de duas visões do mundo antagónicas.

Abstract - Within the frame of diffusion of scientist ideology, Miguel Bombarda is considered as one of the most enlightened intellectuals. By assuming a monist conception of the universe, he contradicted an ideological conservatism sustained by catholic thinkers. Therefore, the Church rose to the challenge of Bombarda's materialism through one of its most enlightened members, the Jesuit Manuel Fernandes Santana. Influenced by materialist thinkers - Haeckel, Molescholt, Verworn, Vogt, Buchner e Darwin -, the Professor of the Medical-Surgical School used his knowledge in the areas of biology, sociology, experimental psychology and other sciences in order to found his theory about the origins of life, self-sufficiency of matter, and human being's conscience and morals. By assuming the idea of science and believing in obtaining scientific truth through a rational path, he denied ideological visions of the universe. However, as far as we are concerned, cosmic determinism eliminated the idea of freedom since the human being lost the capacity of orientating his activity. Therefore, the human being's submission to a blind causalism and the rejection of free-will led Bombarda to eliminate the value of man and freedom, to a certain extent. Unaware of dialectical determinism, he imprisoned the individual in a closed universe, subordinated to the fatality of a phenomenical movement, which is predetermined by immanentist causalism.

To oppose Miguel Bombarda's monism, Father Manuel Fernandes Santana proposed a dualist conception of the cosmos. In his point of view, the order pre-established by God and matter, movement, cosmic energies and their original orientation had their ultimate explanation in the supreme architect that had conceived them. In this perspective, the priest refused mechanicist materialism and reaffirmed the catholic doctrine based on the link between body and soul. Created in the image of God, the human being had the capacity to act on the world that surrounded him. Fernandes Santana thus refuted the determinism defended by Miguel Bombarda, but fell into a dualist conception with no scientific basis whatsoever. The controversy between these two intellectuals showed the radicalism of opposed discourses, which emerged from two antagonist visions of the world. 
(Página deixada propositadamente em branco) 


\section{Colecção \\ Ciências e Culturas \\ Cuimbra 2006}

